\title{
Editorial
}

Psychotherapy

and Psychosomatics

\section{From the Lesson of George Engel to Current Knowledge: The Biopsychosocial Model 40 Years Later}

\author{
Giovanni A. Fava ${ }^{a, c}$ Nicoletta Sonino ${ }^{b, c}$ \\ ${ }^{a}$ Department of Psychology, University of Bologna, Bologna, and ${ }^{b}$ Department of Statistical Sciences, University of \\ Padova, Padova, Italy; ${ }^{C}$ Department of Psychiatry, State University of New York at Buffalo, Buffalo, NY, USA
}

Forty years ago, George L. Engel (1913-1999), a prominent scholar in the psychosomatic movement of the past century, published "The Need for a New Medical Model: A Challenge for Biomedicine" in Science [1]. The article had a considerable impact on the scientific community and attracted more than 3,500 citations in the Web of Science. Interestingly, the flow of citations did not appear to fade over the years and, indeed, it has increased in the last decade. A possible reason is the fact that Engel identified the early signs of the scientific, clinical, and intellectual inadequacies of the traditional biomedical model that became progressively more pronounced.

His main criticism was concerned with reductionism, the tendency to view complex clinical phenomena as ultimately derived from a single primary cause (e.g., genetic) instead of using a multifactorial frame of reference. Engel pointed to the dangers of the alliance between commercial interests in medicine and biomedical reductionism [1]. Indeed, corporate interest in medical science is likely to highlight the importance of single etiological factors and therapeutic agents in the management of disease. $\mathrm{He}$ anticipated the current medical scenario dominated by special interest groups: influential randomized trials are generally done by and for the benefits of the industry, guidelines serve vested interests, national and federal re-

\section{KARGER}

(C) 2017 S. Karger AG, Basel

E-Mail karger@karger.com

www.karger.com/pps search funds are unable to address basic clinical questions [2]. An important drive to reductionism has been determined by the growth of evidence-based medicine that is likely to concentrate on single factors, failing to give suitable weight to clinical variations and all therapeutic components [3-5]. Personalized/precision medicine, referred to as genomics-based knowledge, has promised to approach each patient as the biological individual he or she is [6-8]. However, the practical applications still have a long way to go $[6,9]$ and the neglect of psychological and social features may actually lead to a "depersonalized" medicine [6].

A second major criticism of the traditional medical model addressed the lack of integration of advances in behavioral and social sciences within clinical medicine [1], in a scenario where almost all of health care spending is directed at biomedically oriented interventions. In the past 4 decades a large body of research has documented the following:

1. Stressful life events and repeated or chronic environmental challenges play a role in modulating individual vulnerability to illness $[10,11]$.

2. The tendency to experience and communicate psychological distress in the form of physical symptoms and to seek medical help for them is a widespread clinical

Giovanni A. Fava, MD

Department of Psychology, University of Bologna

Viale Berti Pichat, 5

IT-40127 Bologna (Italy)

E-Mail giovanniandrea.fava@unibo.it 
phenomenon that may involve up to $30-40 \%$ of medical patients and increases medical utilization and costs [12].

3. Affective disturbances, such as depression and anxiety, as well as illness behavior (the ways in which individuals experience, perceive, evaluate, and respond to their own health status), may affect the course, therapeutic response, and outcome of any given illness episode [3].

4. Psychological well-being and resilience have been found to play a protective role in the dynamic balance between health and disease [13-15]. Thus, the need to include consideration of function in daily life, productivity, performance of social roles, intellectual capacity, and emotional stability and well-being, has emerged as a crucial part of clinical investigation and patient care [3].

Another major criticism was on the traditional concept of disease, which tends to be restricted to what can be understood or recognized by the physician [1]. Engel underscored the paradox of patients feeling sick who are assured they are well by a lack of abnormal laboratory findings [1]. Today the changed spectrum of health conditions (e.g., multimorbidity, chronicity) points to the inadequacies of a medical care that is centerd primarily on the diagnosis and treatment of each disease separately [16]. The aim of treatment should be the identification of all modifiable biological and nonbiological factors, and the attainment of individual goals [16]. Accordingly, the traditional boundaries among medical specialties, based mostly on organ systems (e.g., cardiology, gastroenterology) appear to be more and more inadequate in dealing with symptoms and problems that require an integrated approach [3].

Engel thought that the transition from the narrow biomedical model to the biopsychosocial model was the major challenge to medicine at the turn of the century [17]. His model allows illness to be viewed as a result of interacting mechanisms at the cellular, tissue, organismic, interpersonal, and environmental level, as essential components of the whole system [1]. He particularly emphasized the physician's ability to influence and modify the patient's behavior in healthy directions [1]. Improvements in a patient's symptoms that can be attributed to fruitful therapeutic encounters are phenomena that rely on complex neurobiological mechanisms and involve neurotransmitters and specific brain areas [18, 19]. The recent position statement of the American Diabetes Association on the psychosocial care for people with diabetes [20] is in line with this perspective.
As Richardson [21] remarked, the practice of evidence-based medicine should involve the care of whole persons and this makes Engel's approach more timely than ever. Indeed, in its original definition, evidencebased medicine was about "integrating individual clinical expertise with the best external evidence" [22]. The problem is that "external evidence" is manipulated and misused to support financial conflicts of interest [23]. The net result is that it drives the prescribing clinician to an overestimated consideration of potential benefits, paying little attention to the likelihood of responsiveness and to potential vulnerabilities in relation to the adverse effects of treatment [4]. The clinician who adheres to guidelines is convinced to apply the best evidence, and is not aware that he/she is simply guided to see problems in a certain way and to treat the average patient instead of individual needs, degrading clinical practice [4]. There is no simple "average" solution to most medical problems. The question is how to put the available evidence within the context of individual unique assets and liabilities.

As Horwitz et al. [6] remarked, "what is needed to complement the power of genomics is an emphasis on personal attributes of patients and their environments, and to incorporate these features into an enriched approach to personalized medicine" (p. 1156). Medicine is ultimately about relationships and healing. Technological tools for disease management $[7,8]$ do not diminish the need for being scientific in the human domain. The new models and discoveries in science will hopefully acknowledge and fully incorporate Engel's biopsychosocial construct. This would also imply a better communication and interplay between psychosomatic evidence and biomedical advances.

\section{Disclosure Statement}

The authors have no conflicts of interest to declare.

\footnotetext{
References

1 Engel GL: The need for a new medical model: a challenge for biomedicine. Science 1977; 196:129-136.

2 Ioannidis JPA: Evidence-based medicine has been hijacked: a report to David Sackett. J Clin Epidemiol 2016;73:82-86.

3 Fava GA, Cosci F, Sonino N: Current psychosomatic practice. Psychother Psychosom 2017;86:13-30.

4 Fava GA: Evidence-based medicine was bound to fail: a report to Alvan Feinstein. J Clin Epidemiol 2017;84:3-7.
}

Fava/Sonino 
5 Horwitz RI, Hayes-Conroy A, Singer BH: Biology, social environment, and personalized medicine. Psychother Psychosom 2017;86: 5-10.

6 Horwitz RI, Cullen MR, Abell J, Christian JB: (De)personalized medicine. Science 2012; 339:1155-1156.

7 Collins FS, Varmus H: A new initiative on precision medicine. N Engl J Med 2015;372: 792-795.

8 Korngiebel DM, Thummel KE, Burke W: Implementing precision medicine. Trends Pharmacol Sci 2017;38:8-14.

9 Dubovsky SL: The limitations of genetic testing in psychiatry. Psychother Psychosom 2016;85:129-135.

10 McEwen BS: Protective and damaging effects of stress mediators. N Engl J Med 1998;338: 171-179.

11 McEwen BS: Epigenetic interactions and the brain-body communication. Psychother Psychosom 2017;86:1-4.
12 Croicu C, Chwastiak I, Katon W: Approach to the patient with multiple somatic symptoms. Med Clin North Am 2014;98:1079-1095.

13 Southwick SM, Charney DS: The science of resilience: implications for the prevention and treatment of depression. Science 2012; 338:79-82.

14 Hasler G: Well-being: an important concept for psychotherapy and psychiatric neuroscience. Psychother Psychosom 2016;85:255261.

15 Fava GA: Well-Being Therapy: Treatment Manual and Clinical Applications. Basel, Karger, 2016.

16 Tinetti ME, Fried TR, Boyd CM: Designing health care for the most chronic condition multimorbidity. JAMA 2012;307:2493-2494.

17 Engel GL: From biomedical to biopsychosocial. Psychother Psychosom 1997;66:57-62.
18 Kaptchuk TJ, Miller FG: Placebo effects in medicine. N Engl J Med 2015;373:8-9.

19 De las Cuevas C, de Leon J: Reviving research on medication attitudes for improving pharmacotherapy: focusing on adherence. Psychother Psychosom 2017;86:73-79.

20 Young-Hyman D, de Groot M, Hill-Briggs F, Gonzalez JS, Hood K, Peyrot M: Psychosocial care for people with diabetes: a position statement of the American Diabetes Association. Diabetes Care 2016;39:2126-2140.

21 Richardson WS: The practice of evidencebased medicine involves the care of whole persons. J Clin Epidemiol 2017;84:18-21.

22 Sackett DL, Rosenberg WM, Gray JA, Haynes RB, Richardson WS: Evidence-based medicine: what it is and what it isn't. BMJ 1996;312: 71-72.

23 Ioannidis JPA: Hijacked evidence-based medicine: stay the course and throw the pirates overboard. J Clin Epidemiol 2017;84: 11-13. 